\title{
Sequence Defined Disulfide-Linked Shuttle for Strongly Enhanced Intracellular Protein Delivery
}

\author{
Kevin Maier,* Irene Martin, and Ernst Wagner \\ Pharmaceutical Biotechnology, Center for System-Based Drug Research, and Center for Nanoscience, Ludwig-Maximilians-University \\ Munich, Butenandtstrasse 5-13, 81377 Munich, Germany
}

\section{Supporting Information}

ABSTRACT: Intracellular protein transduction technology is opening the door for a promising alternative to gene therapy. Techniques have to address all critical steps, like efficient cell uptake, endolysosomal escape, low toxicity, while maintaining full functional activity of the delivered protein. Here, we present the use of a chemically precise, structure defined threearm cationic oligomer carrier molecule for protein delivery. This carrier of exact and low molecular weight combines good cellular uptake with efficient endosomal escape and low toxicity. The protein cargo is covalently attached by a

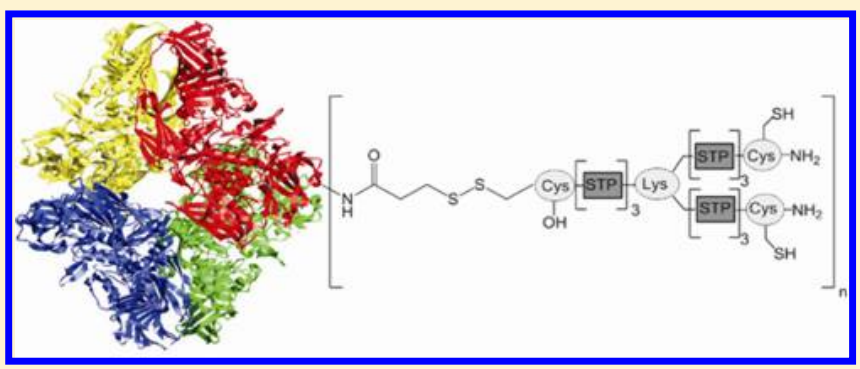
bioreversible disulfide linkage. Murine 3T3 fibroblasts could be transduced very efficiently with cargo nlsEGFP, which was tagged with a nuclear localization signal. We could show subcellular delivery of the nlsEGFP to the nucleus, confirming cytosolic delivery and expected subsequent subcellular trafficking. Transfection efficiency was concentration-dependent in a directly linear mode and 20-fold higher in comparison with HIV-TAT-nlsEGFP containing a functional TAT transduction domain. Furthermore, $\beta$-galactosidase as a model enzyme cargo, modified with the carrier oligomer, was transduced into neuroblastoma cells in enzymatically active form.

KEYWORDS: drug delivery, protein transduction, protein conjugate, polymer, $\beta$-galactosidase

\section{INTRODUCTION}

Today many different proteins, including recombinant growth factors and monoclonal antibodies, are used in cancer therapy and modern medicine. ${ }^{1,2}$ However, up to date application in therapy is largely limited to proteins whose site of action is extracellular at the surface of target cells. Cytosolic delivery of proteins, due their size and charge, for a long time has been conceived as impractical. The first observed protein that was naturally able to translocate through the intact phospholipid bilayer was the HIV-1 TAT protein. ${ }^{3,4}$ In the meantime, it has been discovered that natural homeoproteins such as the Antennapedia homeobox can cross cell membranes and internalize into cells as part of their physiological function, ${ }^{5}$ and numerous homeoprotein-derived natural and artificial transduction peptides have been identified. ${ }^{6-9}$ Thus, the intracellular delivery of active proteins, named protein transduction, now is considered as an interesting option and alternative to gene therapy, substituting for dysfunctional cellular proteins. ${ }^{10-12}$ Protein transduction is expected to be a safe approach, lacking the introduction of potentially recombinogenic nucleic acid material. ${ }^{13}$ In addition, the technology offers the possibility to transport chemically modified proteins, containing, for example, artificial or Damino acids, considered to be less immunogenic and more stable toward proteolytic degradation. On the bench side, intracellular protein delivery technology offers innumerable possibilities, like localization, interaction, and many other studies. For in vitro studies, it is possible to use physical methods, like microinjection or electroporation, to promote an uptake of the desired protein. ${ }^{14,15}$ Alternatively, such as for therapeutic application, a transfection carrier molecule is needed. The transfection carrier has to prevent the cargo from extracellular degradation and has to transport it across the biological barrier of the cell membrane. Once inside the cell, the carrier-cargo complex has to avoid endolysosomal degradation either by direct transfer into the cytosol or by escape from endolysosomal vesicles after endocytosis. Afterward, the carrier should release its cargo in the cytosol or be sufficiently inert to warrant full functional activity of the protein. A perfect carrier system should combine all these entry functions with low cytotoxicity. In the last decades, many efforts have been made to create such a perfect carrier system. Aside from rather exotic technologies, for example, virus-like particles, ${ }^{16}$ carbon nanotubes, ${ }^{17,18}$ and mesoporous silica, ${ }^{19,20}$ the most common techniques are protein delivery with cationic lipids, ${ }^{21,22}$ protein transduction domains (PTDs), ${ }^{11,23-25}$ and cationic polymers. ${ }^{26-31}$ Each of these technologies has got its limitations such as cell type dependence ${ }^{32}$ or borders certain cargo proteins. ${ }^{33}$ Most commercially available protein trans-

Received: July 25,2012

Revised: November 6, 2012

Accepted: November 9, 2012

Published: November 9, 2012 
fection shuttles are based on cationic lipids. A major drawback of this technology is low stability under serum conditions. ${ }^{34}$ Protein delivery with cell penetrating peptides, which can be grouped in two major classes, natural ones like penetratin ${ }^{25,35}$ or HIV-TAT ${ }^{11}$ and artificial ones such as oligoarginines, ${ }^{32}$ is the best investigated strategy. Protein transduction domains (PTDs) or cell penetrating peptides (CPPs) as they are also commonly called are tagged to the cargo protein by genetic engineering. Especially in cases where the active center of an enzyme is located near the carboxy- or amino-terminus, this tag may disturb functionality. The internalization pathway of these fusion proteins is controversial. Some studies suggest macropinocytosis, ${ }^{36,37}$ others predict that it is a mixture between different mechanisms. ${ }^{38-40}$ The efficiency of the following step, the retrograde transport out of the endosome is low for most PTDs $^{41,42}$ and dependent on cell line and cargo size. ${ }^{32,39}$ Cationic transfection polymers like polyethylenimine often are very effective but are lacking of precise structure and often show high toxicity dependent on the molecular weight of the used polymer. ${ }^{27-30,43}$

In this study, we investigate the properties of the three-arm cationic oligomer 386 as a shuttle for intracellular protein delivery. This carrier molecule, in contrast to other cationic polymers used for intracellular delivery, is of precise structure and low molecular weight. In contrast to structure defined carriers, purification, analytics, reproducibility, and a clear structure-activity relationship are problematic steps when using polymers of distributed molecular weight. Oligomer 386 was recently designed for siRNA delivery. ${ }^{44,45}$ Protein delivery places different demands on a carrier than nucleic acid delivery. While the use as a nucleic acid carrier was based on electrostatic complex formation, this is not generally feasible for proteins, which exhibit much lower charge densities, varying from protein to protein. The transfection oligomer 386 was covalently bound to cargo proteins ( $\beta$-galactosidase or enhanced green fluorescent protein) by a bioreversible disulfide bond. Covalent coupling of the carrier $\mathbf{3 8 6}$ was indispensable for forming an effective transduction shuttle. Such disulfide conjugations have been previously shown to be reversible upon cytosolic delivery. ${ }^{46,47}$ Our results reveal that covalent disulfide coupling of the defined cationic oligomer 386 to a protein leads to a highly efficient (even in presence of serum) and low toxic alternative to established protein transfection technologies.

\section{EXPERIMENTAL SECTION}

General. All chemicals were purchased from Sigma-Aldrich (Taufkirchen, Germany), unless noted otherwise. SPDP ( $N$ succinimidyl 3-(2-pyridyldithio) propionate) was synthesized as described elsewhere. ${ }^{48} \beta$-Galactosidase from E. coli (EC: $232-$ 864-1) was purchased from Sigma-Aldrich (Taufkirchen, Germany). Neuro2A neuroblastoma cells (ACC-148) and the murine fibroblast cell line NIH-3T3 (ACC 59) were purchased from DSMZ (Braunschweig, Germany).

Cloning, Heterologous Expression, and Purification of nlsEGFP and HIV-TAT-nlsEGFP. nlsEGFP was prepared analogously as described previously. ${ }^{49}$ HIV-TAT-nlsEGFP was prepared by annealing and cloning the following oligonucleotides encoding for HIV-TAT sequence into the heterologous expression of the nlsEGFP designed vector. ${ }^{49}$ Sense: 5'AGCTTGGTTATGGGCGCAAAAAACGCCGTCAGCGCCGTCGGGGCC3'. Antisense: 5'TCGAGGCCCCGACGGCGCTGACGGCGTTTTTTGCGCCCATAACCA 3'.
By the common calcium chloride method, this plasmid was transformed into E. coli BL21(DE3)plysS (Novagen, Merck4biosciences, Darmstadt, Germany). Under constant shaking in TB medium $\left(37^{\circ} \mathrm{C}\right)$, the cells were grown to an optical density of $0.75(600 \mathrm{~nm})$. Protein expression was induced with isopropyl $\beta$-D-1-thiogalactopyranoside (Biomol, Hamburg, Germany) (final concentration $1 \mathrm{mM}$ ), and expression was continued for another $16 \mathrm{~h}$. After ultrasonic cell lysis, the nlsEGFP was purified by nickel chromatography using a gradient from binding buffer $(50 \mathrm{mM}$ sodium hydrogen phosphate, $300 \mathrm{mM}$ sodium chloride, and $20 \mathrm{mM}$ imidazole) to elution buffer ( $50 \mathrm{mM}$ sodium hydrogen phosphate, 500 $\mathrm{mM}$ sodium chloride, and $250 \mathrm{mM}$ imidazole). The protein was dialyzed overnight at $4{ }^{\circ} \mathrm{C}$ against PBS buffer ( $\mathrm{pH}$ 7.3) using a dialysis membrane (MWCO 14,000 Da) from Carl Roth (Karlsruhe, Germany). Finally, the TAT-nlsEGFP was concentrated with an Amicon Ultra centrifugal filter units (MWCO 10,000 Da).

Modification of Cargo Proteins with an SPDP Linker Molecule. Modification of $\beta$-Galactosidase. $\beta$-Galactosidase ( $3 \mathrm{mg}, 0.026 \mu \mathrm{mol})$ was diluted in PBS buffer $(1 \mathrm{~mL}$; pH 7.3, 1 mM EDTA). Then, SPDP (succinimidyl 3-(2-pyridyldithio)propionate) was dissolved in DMSO $(50 \mu \mathrm{L} ; 0.775 \mu \mathrm{mol})$ and added to the above protein solution (30-fold molar excess compared to $\beta$-galactosidase). After incubation $\left(2 \mathrm{~h} ; 20{ }^{\circ} \mathrm{C}\right)$, the unconjugated linker was removed by size exclusion chromatography (Sephadex G25 superfine) using PBS buffer ( $\mathrm{pH} 7.3,1 \mathrm{mM}$ EDTA) as the mobile phase. The modified protein was concentrated with Amicon Ultra centrifugal filter units (MWCO 10,000; Millipore (Billerica, MA)). The protein concentration was determined at $280 \mathrm{~nm}$ using a molar extinction coefficient of $210000 \mathrm{M}^{-1} \mathrm{~cm}^{-1}$. The ratio of linker to protein could be calculated, after reducing a sample of the modified protein with DTT (dithiothreitol) and determination of the change in absorbance $\left(343 \mathrm{~nm} ; 8080 \mathrm{M}^{-1} \mathrm{~cm}^{-1}\right)$.

Modification of nlsEGFP. nlsEGFP ( $3 \mathrm{mg}, 0.095 \mu \mathrm{mol})$ was diluted in PBS buffer ( $1 \mathrm{~mL}$; pH 7.3, $1 \mathrm{mM}$ EDTA). Then SPDP (succinimidyl 3-(2-pyridyldithio)propionate) was dissolved in DMSO ( $50 \mu \mathrm{L} ; 1.14 \mu \mathrm{mol})$ and added to the above protein solution. After incubation $\left(2 \mathrm{~h} ; 20{ }^{\circ} \mathrm{C}\right)$, the unconjugated linker was removed by size exclusion chromatography (Sephadex G25 superfine) using PBS buffer ( $\mathrm{pH} 7.3,1$ $\mathrm{mM}$ EDTA) as the mobile phase. The modified protein was concentrated with Amicon Ultra centrifugal filter units (MWCO 10,000 Da; Millipore (Billerica, MA)). Protein concentration was quantified by measurement of the absorbance at a wavelength of $488 \mathrm{~nm}$ using an extinction coefficient of $55000 \mathrm{M}^{-1} \mathrm{~cm}^{-1}$. The ratio of linker to protein could be calculated, after reducing a sample of the modified protein with DTT (dithiothreitol) and determination of the change in absorbance $\left(343 \mathrm{~nm} ; 8080 \mathrm{M}^{-1} \mathrm{~cm}^{-1}\right)$.

Conjugation of Proteins with Transfection Oligomer 386. Transfection oligomer 386 was synthesized as previously reported. ${ }^{44}$ SPDP modified proteins $(1 \mathrm{mg})$ were diluted in Hepps buffer ( $1 \mathrm{~mL}, 0.5 \mathrm{M}, \mathrm{pH} 8.5)$ and 2-fold molar excess of oligomer 386 (compared to covalently bound linker), which was predissolved in water $(50 \mathrm{mg} / \mathrm{mL})$, was added for the modification of nlsEGFP. For the modification of $\beta$ galactosidase, a 5-fold molar excess of oligomer 386 (compared to covalently bound linker), which was predissolved in water $(50 \mathrm{mg} / \mathrm{mL})$, was used. Thereafter, the $\mathrm{pH}$ was adjusted to 7.5 with aqueous $\mathrm{HCl}(1 \mathrm{M})$ in both cases. The product was purified, after $1 \mathrm{~h}$ of incubation $\left(20^{\circ} \mathrm{C}\right)$ by Amicon Ultra 
centrifugal filter units (MWCO 10,000 Da; 3× washing steps with PBS buffer and $1 \mathrm{mM}$ EDTA, $\mathrm{pH} 7.3$ ).

Cell Culture. 3T3 murine fibroblasts cells were grown in Dulbecco's modified Eagle's medium (DMEM), supplemented with FCS $(10 \%)$, glucose $(4 \mathrm{~g} / 1)$, stable glutamine $(4 \mathrm{mM})$, sodium pyruvate $(1 \mathrm{mM})$, penicillin $(100 \mathrm{U} / \mathrm{mL})$, and streptomycin $(100 \mu \mathrm{g} / \mathrm{mL})$. Neuro2A were cultured in DMEM (1.0g/L glucose) supplemented with FCS (10\%), and $100 \mathrm{U} / \mathrm{mL}$ penicillin and streptomycin $(100 \mu \mathrm{g} / \mathrm{mL})$. All cells were cultured in a $37{ }^{\circ} \mathrm{C}$ incubator with $5 \% \mathrm{CO}_{2}$ supply and humidified atmosphere.

Cell Viability Assay. The metabolic activity of transfected cells was determined by the MTT assay. Neuro2A or 3T3 cells were seeded in 96-well tissue culture plates (TPP, Transdingen, Switzerland) at a density of 15000 cells per well, the day before transfection. Cells were transfected with different concentrations of 386-SS-nlsEGFP $(0.1 ; 0.25 ; 0.5 ; 0.75 ; 1.0 ; 1.5 ; 2.0$; $2.5 \mu \mathrm{M}$ ) in $100 \mu \mathrm{L}$ of growth media (containing $10 \%$ FCS) for $2 \mathrm{~h}$. After washing with PBS and incubating in fresh media (24 h), MTT solution (10 $\mu \mathrm{L}$ per well, $5.0 \mathrm{mg} / \mathrm{mL}$ MTT in phosphate-buffered saline, $\mathrm{pH}$ 7.4) was added. The medium was replaced by $100 \mu \mathrm{L}$ of DMSO after $3 \mathrm{~h}$. The optical absorbance was measured at $590 \mathrm{~nm}$, with a reference wavelength of $630 \mathrm{~nm}$, by a microplate reader (Spectraflour Plus, Tecan Austria GmbH, Austria). The metabolic activity of the transduced cells was expressed as relative cell viability, compared to untreated cells.

$\boldsymbol{\beta}$-Galactosidase Transfection. Neuro2A cells were seeded in 6 well plates $(250000$ cells per well; one day before transfection) and transfected with 1 or $2.5 \mu \mathrm{M}$ 386- $\beta$ galactosidase (in cell culture media containing 10\% FCS) for 2 h. For X-Gal staining, a method which was previously described was used. ${ }^{50}$ After transfection, cells were washed with PBS (containing $500 \mathrm{IU}$ heparin per $\mathrm{mL}$ and subsequently fixed with $(1.25 \%$ (v/v) glutaraldehyde). Following two additional washing steps with PBS, X-gal staining solution (50 mMTris/ $\mathrm{HCl} ; \mathrm{pH} 7.5 ; 5 \mathrm{mM}$ potassium ferrocyanate, $5 \mathrm{mM}$ potassium ferricyanate, $15 \mathrm{mM}$ sodium chloride, $1 \mathrm{mM}$ magnesium chloride, $0.1 \%$ Triton, and $0.5 \mathrm{mg} / \mathrm{mL} \mathrm{X-gal)} \mathrm{was} \mathrm{added} \mathrm{and}$ incubated for $3 \mathrm{~h}\left(37^{\circ} \mathrm{C}\right)$. Afterward, the cells were washed once more with PBS and analyzed with a phase contrast microscope. For quantitative flow cytometric analysis, C12FDG (Invitrogen, Karlsruhe, Germany) substrate was used. Neuro2A cells (250000) were seeded in 6 well plates the day before transfection. Transfection was done by pipetting 386-SS$\beta$-galactosidase into the growth media. After $2 \mathrm{~h}$ of incubation, the cells were washed two times with PBS buffer supplemented with $500 \mathrm{IU}$ heparin per $\mathrm{mL}$. Afterward, the cells were covered with fresh growth media containing $2.0 \mu \mathrm{M}$ C12-FDG. After incubation for $45 \mathrm{~min}$, the cells were washed again with PBS and evaluated by flow cytometry.

nlsEGFP Transfection Experiments. For fluorescence microscopy, $24 \mathrm{~h}$ prior to transfection 20000 cells were seeded in 8 well Nunc chamber slides (Thermo Scientific, Braunschweig, Germany). Before transfection, the medium was replaced with fresh medium. Subsequently, the oligomer modified nlsEGFP was pipetted (final concentration $1 \mu \mathrm{M}$ ) into cell culture media (10\% FCS). After $2 \mathrm{~h}$ of incubation, the cells were washed with PBS buffer ( $\mathrm{pH} 7.3$ ) containing $500 \mathrm{IU}$ heparin per $\mathrm{mL}$. Afterward, fresh medium was added, and $2 \mathrm{~h}$ later, the cells were examined under the microscope. For FACS experiments, $24 \mathrm{~h}$ prior to transfection 250000 cells were seeded in 6-well plates. Before transfection, the medium was replaced with fresh medium containing $10 \%$ FCS. Subsequently, the oligomer modified nlsEGFP was pipetted into the cell culture media (usually $0.5 \mu \mathrm{M}$, except for the uptake vs concentration experiment $0.25 ; 0.5 ; 0.75 ; 1.0 ; 1.5 \mu \mathrm{M})$. After incubation (usually $120 \mathrm{~min}$, except for the uptake vs time experiment $15 ; 30 ; 60 ; 120 ; 180 \mathrm{~min})$, cells were washed two times with PBS buffer ( $\mathrm{pH} 7.3$; $500 \mathrm{IU}$ heparin per $\mathrm{mL}$ ).

Flow Cytometry. 3T3 or Neuro2A cells were seeded in 6well plates (250000 cells/well). After transfection and washing as described above, cells were detached with trypsin/EDTA, diluted with growth media containing $10 \%$ FCS, harvested by centrifugation, and taken up in phosphate-buffered saline with $10 \%$ FCS. Flow cytometry was performed using a Cyan ADP flow cytometer (Dako, Hamburg, Germany). The cellular fluorescence was assayed by excitation of nlsEGFP or C12FDG at $488 \mathrm{~nm}$ and detection of emission at $510 \mathrm{~nm}$. To discriminate between viable and dead cells as well as for exclusion of doublets, cells were appropriately gated by forward/sideward scatter and pulse width, and counterstained with propidium iodide. Ten thousand gated cells per sample were collected. Data was recorded with SummitT software (Summit, Jamesville, NY). Evaluation was done using FlowJo software (Treestar, Ashland, Oregon, USA).

Endocytosis Inhibition. This experiment was performed as described elsewhere, ${ }^{31}$ with minor modifications. Briefly, 250000 cells were seeded in 6 well plates. Before transfection, the medium was replaced with fresh medium containing $1 \mathrm{mM}$ amiloride (inhibitor for macropinocytosis), $5 \mu \mathrm{g} / \mathrm{mL}$ chloropromazine (inhibitor for clathrin-mediated endocytosis), or $2.5 \mathrm{mM} \beta$-cyclodextrin (inhibitor for caveolae-mediated endocytosis). After $30 \mathrm{~min}$ of incubation, the oligomer modified nlsEGFP was pipetted into the cell culture media $(0.5 \mu \mathrm{M})$. After $120 \mathrm{~min}$, cells were washed two times with PBS buffer ( $\mathrm{pH} 7.3,500$ IU heparin per $\mathrm{mL}$ ) and subsequently analyzed by flow cytometry.

Particle Size and Zeta Potential. Particle size and zeta potential of the transfection shuttles were measured by dynamic laser-light scattering using a Zetasizer Nano ZS (Malvern Instruments, Worcestershire, UK). Modified proteins were measured in Hepes buffer $(20 \mathrm{mM}, \mathrm{pH} 7.4)$ at a concentration of $5 \mathrm{mg} / \mathrm{mL}$. In investigations of the effect of serum on particle size and zeta potential, 10\% FCS was added.

Fluorescence Microscopy and Phase Contrast Microscopy. For fluorescence microscopy observation, the nuclei of the cells were stained by pipetting Hoechst Dye $33342(1 \mu \mathrm{g} /$ $\mathrm{mL}$ ) into the cell culture media. Ten minutes later, the cells were observed on an Axiovert 200 fluorescence microscope from Zeiss (Jena, Germany). A $40 \times$ phase 1 objective or a $63 \times$ magnification DIC oil immersion objective (Plan-APOCHROMAT) and appropriate filter sets for analysis of EGFP and Hoechst fluorescence were used. Data were analyzed and processed by AxioVision LE software (Zeiss, Jena, Germany). For phase contrast microscopy, also an Axiovert 200 microscope from Zeiss (Jena, Germany) was used. Pictures were taken using a $10 \times$ magnification phase 1 contrast objective.

Activity Test of Modified $\boldsymbol{\beta}$-Galactosidase. The formation of a fluorescent product (4-methylumbelliferone (4-MU); $\lambda_{\text {excitation }} 360 \mathrm{~nm}, \lambda_{\text {emission }} 440 \mathrm{~nm}$ ) out from the nonfluorescent 4 -methylumbelliferone- $\beta$-D-galactopyranosidesubstrate (MUG) by hydrolysis through $\beta$-galactosidase ${ }^{51}$ was used to determine the relative activity of modified $\beta$ galactosidase, compared to that of the unmodified enzyme. The assay was performed with minor modification as described 
Scheme 1. Transfection Concept with Disulfide-linked 386

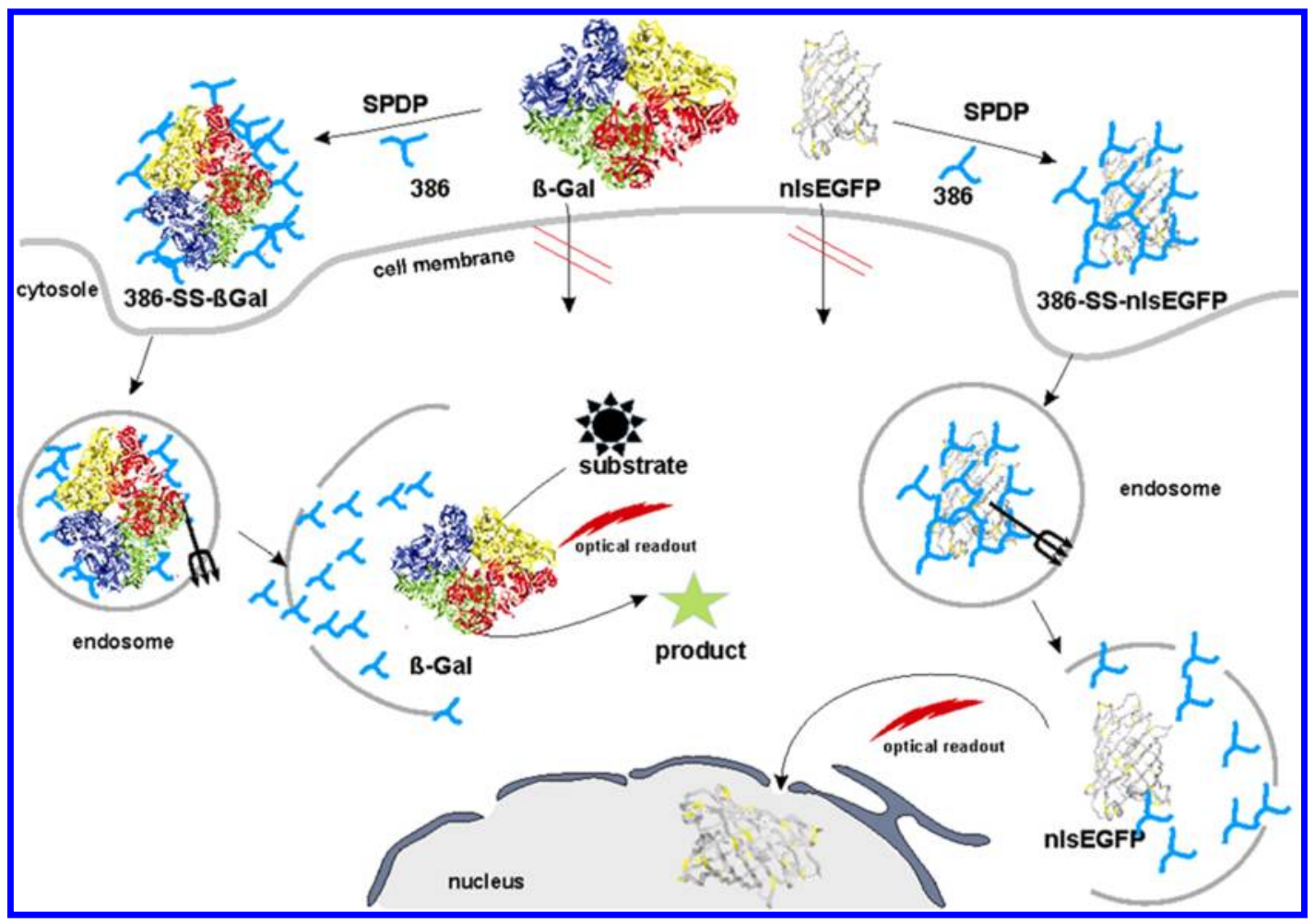

elsewhere. ${ }^{52}$ Briefly, the MUG ( $1 \mathrm{mM}$, nonlimiting surplus) substrate was dissolved in PBS buffer ( $\left.\mathrm{pH} 7.4 ; 5 \mathrm{mM} \mathrm{MgCl}_{2}\right)$. The reaction was started by the addition of enzyme $(0.5 \mu \mathrm{g} /$ $\mathrm{mL}$ ). Enzyme kinetics was monitored by following the formation of the fluorescent 4-MU product over time on a Varian Cary Eclipse fluorescence spectrophotometer. As the substrate was used in nonlimiting surplus, the enzyme activity is displayed by the slope of the curve.

\section{RESULTS AND DISCUSSION}

For evaluating intracellular delivery of proteins, we have chosen two model cargos: $\beta$-galactosidase, a big $464-\mathrm{kDa}$ homotetramer, where enzymatic activity can be checked histochemically and by flow cytometry; and a tagged EGFP protein, which has average protein size $(32 \mathrm{kDa})$ and can be followed in cellular uptake by flow cytometric methods and in intracellular distribution by fluorescence microscopy. A nuclear localization signal (SV40 large T-antigen) tagged EGFP (nlsEGFP) was selected because only free cytosolic nlsEGFP (and not endosomal captured nlsEGFP) can translocate into the nucleus; thus, this feature was utilized to indicate endosomal escape and natural subcellular behavior. ${ }^{53}$ An overview of the transfection concept with disulfide linked 386 is illustrated in Scheme 1.

The covalent attachment of the carrier 386 to the cargo proteins ( $\beta$-galactosidase, nlsEGFP) is schematically displayed in Scheme 2. The biological reversible covalent chemical conjugation between synthetic molecules or peptides and proteins via SPDP linker is a well-established method. ${ }^{54}$ At an average, 5 linker molecules were introduced per EGFP molecule. Each $\beta$-galactosidase molecule was modified with an average of 8 linker molecules.

These linker molecules bearing activated thiol groups were used for the biological reversible covalent attachment of the cationic transfection oligomer $\mathbf{3 8 6}$.
Scheme 2. Modification of $\beta$-Galactosidase (and nlsEGFP) with Transfection Oligomer 386 over the Biocleavable SPDP Linker

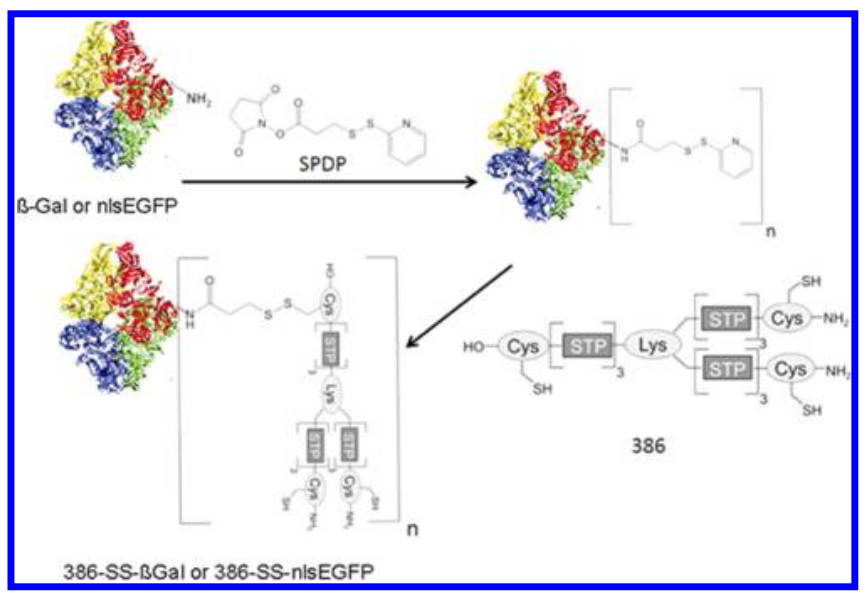

The formed disulfide bonds should be cleavable by glutathione in the cytosol after endosomal release, resulting in a carrier free nlsEGFP or $\beta$-galactosidase. ${ }^{46,55}$ The successful modification and reversibility of the disulfide bonds are documented in Supporting Information, Figure S1.

Dynamic light scattering revealed for 386-conjugates nlsEGFP particle sizes of $26.8 \pm 3.6 \mathrm{~nm}$ and a zeta potential of $12.4 \pm 0.6 \mathrm{mV}$. The presence of $10 \%$ serum decreased zeta potential to $5.32 \pm 0.1 \mathrm{mV}$ and lead to the formation of heterogeneous particles with sizes between 32 and $360 \mathrm{~nm}$. For 386-modified $\beta$-galactosidase, we obtained particles of $48.3 \pm$ $2.4 \mathrm{~nm}$ with a surface charge of $9.5 \pm 0.2 \mathrm{mV}$. In the presence of $10 \%$ FCS, the particle sizes for 386-SS- $\beta$-Gal ranged between 51 and $460 \mathrm{~nm}$, and the zeta potential decreased to $4.49 \pm 0.5$ $\mathrm{mV}$. 
To investigate the ability of these transfection shuttles to penetrate cells and promote endosomal release and natural subcellular transport, cells were transfected as described in the Experimental Section. Uptake and subcellular distribution of nlsEGFP conjugates were pursued using a fluorescence microscope. Figure 1 (top) nicely demonstrates that all cells

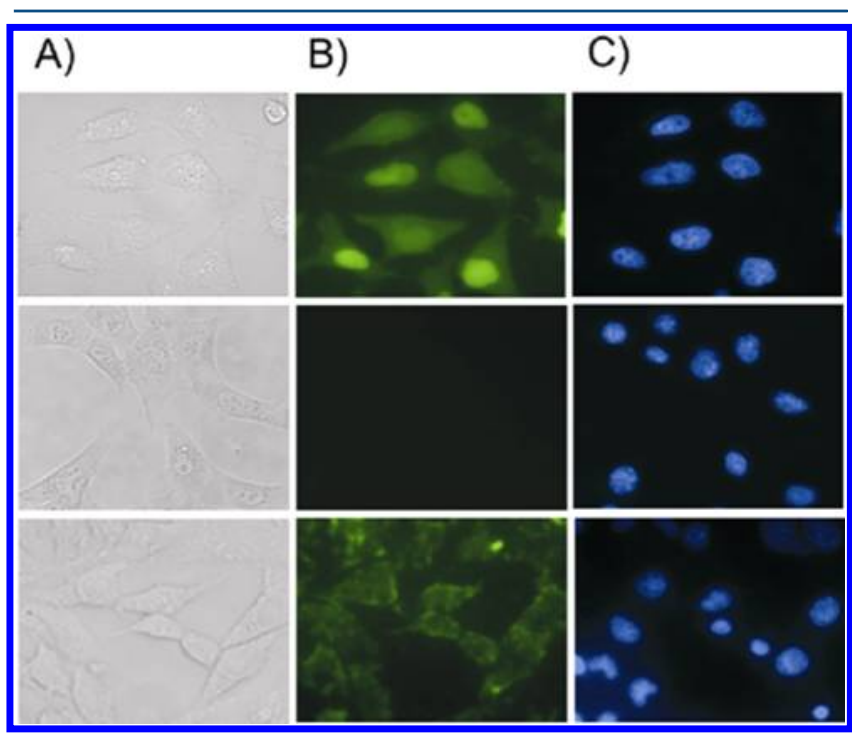

Figure 1. Treatment of 3T3 cells with nlsEGFP. Top: carrier 386 was coupled to nlsEGFP with the SPDP linker. Center: transfection with unmodified nlsEGFP. Bottom: cells were transfected with TATnlsEGFP. (A) Bright-field picture of the transfected cells, (B) EGFP fluorescence of the transfected cells, and (C) Hoechst 33342 DNA stain of the cell nucleus.

were transfected successfully after an incubation time of $2 \mathrm{~h}$, using a $0.5 \mu \mathrm{M}$ concentration of 386-SS-nlsEGFP. The cells show homogeneous cytoplasmic background fluorescence. This suggests endosomal escape of the 386-SS-nlsEGFP. In addition, the protein is concentrated in the nuclei of the cells, confirming successful escape of the transfection shuttles out of the endosomes and subsequent active nuclear import facilitated by the NLS sequence. Cells treated with unmodified nlsEGFP, as a control, do not show any fluorescence (Figure 1 center). Cells transfected with $1.5 \mu \mathrm{M}$ TAT-nlsEGFP also show green fluorescence all over the cells (Figure 1 bottom), but nuclear fluorescence is much lower compared to cells transfected with 386-nlsEGFP.

Efficiency of the protein delivery was studied by transfection of 3T3 cells with different concentrations of 386-modified nlsEGFP in comparison to a TAT-tagged-nlsEGFP fusion protein. Evaluation was done via flow cytometry. Cells transduced with 386-SS-nlsEGFP showed significantly higher fluorescence intensity, when transfected with the same protein concentration, compared to cells with PTD-mediated delivery (Figure 2). The mean cellular fluorescence intensity of 386-SSnlsEGFP-treated cells is about 20 times higher than the mean fluorescence of TAT-nlsEGFP-treated ones. Controls which were treated with a high concentration $(5 \mu \mathrm{M})$ of unmodified nlsEGFP showed only negligible rise in fluorescence.

The same experiment was performed with Neuro2A cells. Transfection efficiency on Neuro2A cells was lower, compared to that of the $3 \mathrm{~T} 3$ cells, when transfected with the same amount of modified protein. The fluorescent intensity of Neuro2A cells compared to that of $3 \mathrm{~T} 3$ cells was around 2 -fold lower for cells

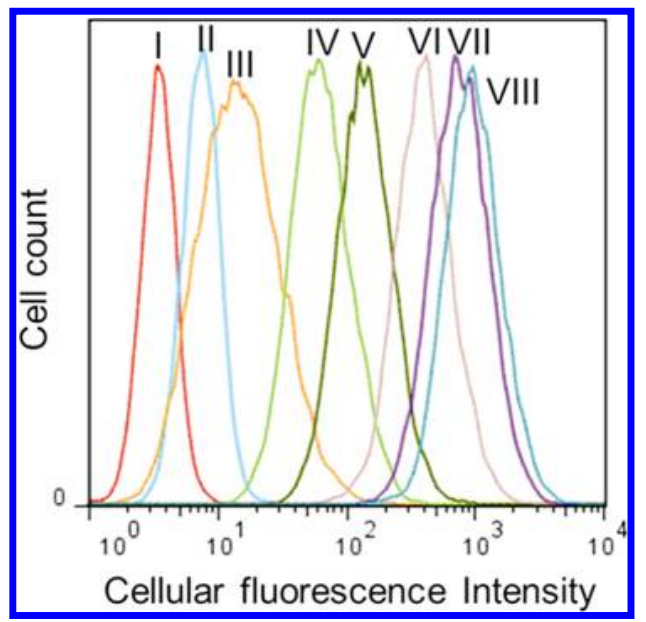

Figure 2. Fluorescence assisted cell sorting of 3T3 murine fibroblasts after transfection with varying concentrations of 386-SS-nlsEGFP in comparison to TAT-nlsEGFP mediated protein transduction. (I) Untreated control cells, (II) $5 \mu \mathrm{M}$ unmodified nlsEGFP, (III) $0.5 \mu \mathrm{M}$ TAT-nlsEGFP, (IV) $1.5 \mu \mathrm{M}$ TAT-nlsEGFP, (V) $0.25 \mu \mathrm{M}$ 386-SSnlsEGFP, (VI) $0.5 \mu \mathrm{M}$ 386-SS-nlsEGFP, (VII) $0.75 \mu \mathrm{M}$ 386-SSnlsEGFP, and (VIII) $1 \mu \mathrm{M}$ 386-SS-nlsEGFP.

transfected with $0.25 \mu \mathrm{M}$; at higher concentrations, the mean fluorescence intensity was around $20 \%$ lower (Figure 3A). All standard transfections were performed in the presence of $10 \%$ fetal bovine serum. To evaluate the influence of serum, a comparison of transfections with (white bars) or without (gray bars) serum was made (Figure $3 \mathrm{~B}$ ). A considerable influence of

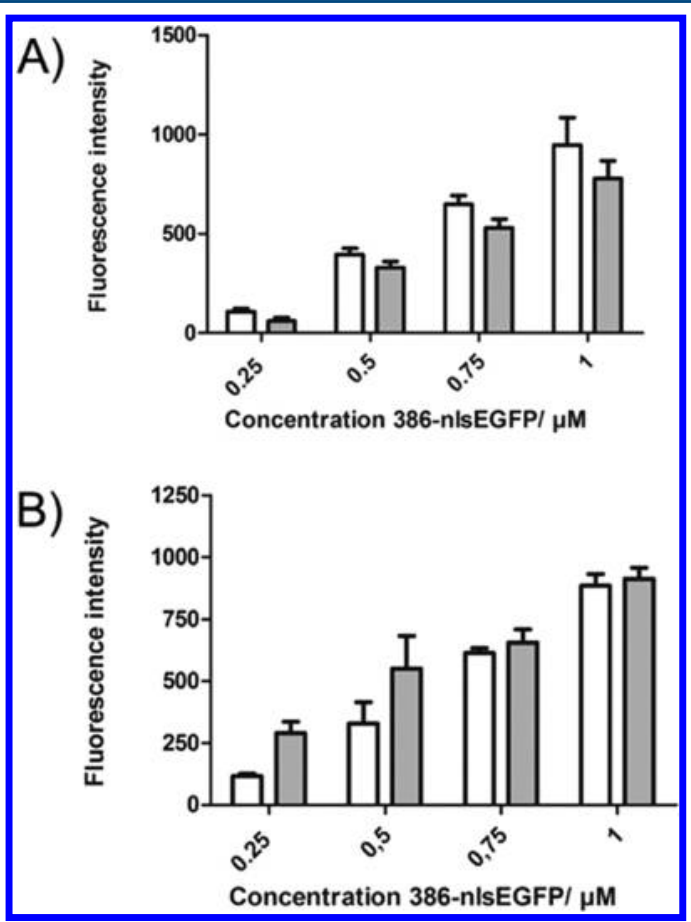

Figure 3. Average cellular EGFP fluorescence intensity of cells transfected with 386-SS-nlsEGFP. (A) Comparison of cellular fluorescence of 3T3 murine fibroblasts (white bars) and Neuro2A cells (gray bars) after transfection with different concentrations of 386SS-nlsEGFP. (B) Influence of serum on transfection efficiency. 3T3 cells treated with 386-SS-nlsEGFP in the presence (white bars) or absence (gray bars) of $10 \%$ FCS. 
serum on transfection efficiency was observed only at transfection concentrations at $0.5 \mu \mathrm{M}$ or lower.

We had expected that the amount of internalized material is concentration dependent, as was already reported for CPPassisted transfection studies. ${ }^{40}$ Nevertheless, we were quite surprised about the nearly perfect linear relationship between concentration of protein transfection conjugate and fluorescence intensity for both cell types in the tested concentration area. Similar linear dependency of concentration and uptake was already reported for internalization mediated by the protein transduction domain Antp (Antennapedia-homeodomain). ${ }^{38}$

In the following experiment, we performed a time-course (Figure 4). Uptake of 386-SS-nlsEGFP increased with incubation time, resulting in the observed increased fluorescence intensity (Figure 4 ).

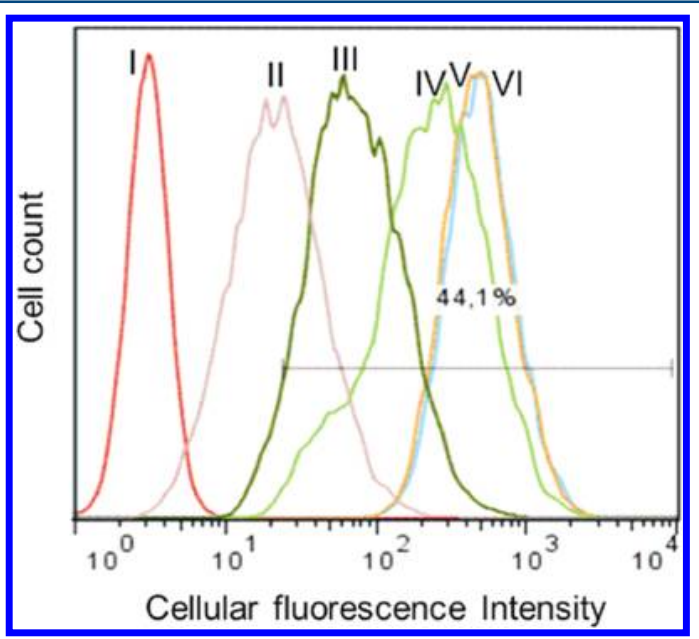

Figure 4. Fluorescence assisted cell sorting of 3T3 murine fibroblasts after transfection with varying transfection time with $0.5 \mu \mathrm{M}$ 386-SSnlsEGFP. (I) Untreated control cells, (II) 15 min incubation, (III) 30 min, (IV) $60 \mathrm{~min}$, (V) $120 \mathrm{~min}$, and (VI) $180 \mathrm{~min}$.

After 15 min of incubation time around $45 \%$ and after 30 min incubation already over $90 \%$ of the cells were EGFP positive when transfection was performed with $0.5 \mu \mathrm{M}$ 386-SSnlsEGFP. Such a continuous uptake is supposed to be a strong hint for endocytosis-mediated uptake. ${ }^{38}$ Transfection at $4{ }^{\circ} \mathrm{C}$ dramatically lowers internalization of the modified protein (Figure 5) in $3 \mathrm{~T} 3$ cells. Cells transfected at $4{ }^{\circ} \mathrm{C}$ exhibited only $25 \%$ of the fluorescence compared to that of control cells transfected at $37{ }^{\circ} \mathrm{C}$. This observation indicates that internalization of 386-modified nlsEGFP is an energy-dependent process and is consistent with most CPPs. ${ }^{31,40,56}$ To further analyze the endocytotic pathway in $3 \mathrm{~T} 3$ cells, we did transfection experiments in the presence of chlorpromazine (inhibits clathrin-mediated endocytosis), amiloride (inhibits macropinocytosis), and $\beta$-cyclodextrin (inhibits caveolaemediated endocytosis). All these endocytosis inhibitors reduced transfection efficiency at least a little bit, suggesting that all three endocytosis pathways participate in internalization. Clathrin-mediated endocytosis is the predominant internalization route, as chlorpromazine reduced fluorescence to $55 \%$ compared to control cells, transfected under standard conditions. Caveolae-mediated endocytosis and macropinocytosis seem to contribute, respectively, to around $15-20 \%$ of the uptake. The finding that clathrin-mediated endocytosis may be the major internalization route is in accordance with the

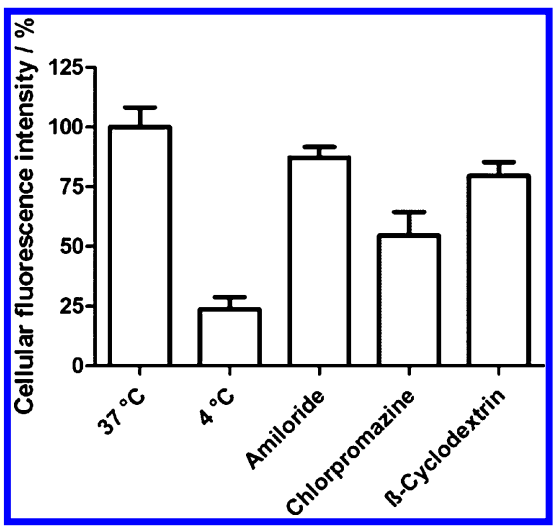

Figure 5. Average cellular fluorescence intensity of $3 \mathrm{~T} 3$ cells after transfection with 386-SS-nlsEGFP at $4{ }^{\circ} \mathrm{C}$ and in the presence of three different endocytosis inhibitors: amiloride, $\beta$-cyclodextrin, and chlorpromazine. Fluorescence intensity is normalized to cells transfected at $37^{\circ} \mathrm{C}$.

measured particle size, as particles smaller than $200 \mathrm{~nm}$ are supposed to be taken up mainly through this pathway. ${ }^{57}$ Aoyama and co-workers found that receptor-mediated endocytosis is strongly size-dependent with an optimum of around $25 \mathrm{~nm} .{ }^{58-60}$ This correlates exactly with the measured size of the transfection shuttles and the observed uptake pathway.

Flow cytometry experiments using $0.5 \mu \mathrm{M}$ 386-SS-nlsEGFP further demonstrate that internalized nlsEGFP disappears after a few days (Figure 6). This finding was expected as due to cell

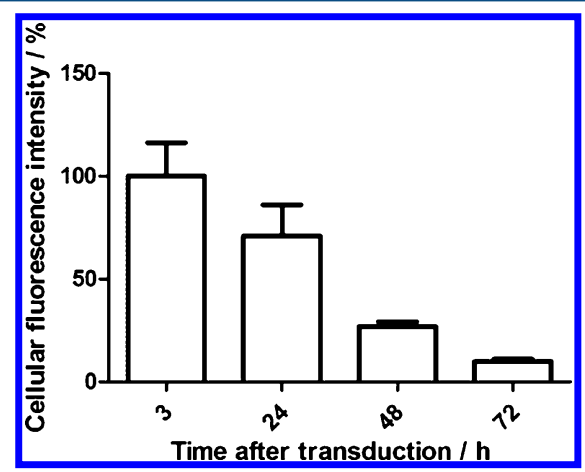

Figure 6. Average cellular fluorescence intensity of $3 \mathrm{~T} 3$ cells at different time points after transfection with 386-SS-nlsEGFP. Fluorescence intensity is normalized to cells analyzed at $3 \mathrm{~h}$ after transfection.

proliferation, the intracellular nlsEGFP concentration is dying out. Another reason might be proteosomal degradation. Twenty-four hours after transfection, the cells lost approximately one-third of their original mean fluorescence. Within 48 $\mathrm{h}$ after transfection, the fluorescence decreased to a fourth and after $72 \mathrm{~h}$ to below $10 \%$ of the primordial value.

In addition to transfection of the fluorescent protein nlsEGFP, transfection of the enzyme $\beta$-galactosidase, a big $464 \mathrm{kDa}$ homotetramer, was evaluated. Disulfide conjugation to 386 resulted in considerably reduced enzyme activity (Figure 7A). A possible reason for this finding may be the disturbance of the tertiary structure of the enzyme due to the charge inversion of the protein, as unmodified $\beta$-Gal is a protein with a negative isoelectric point (theoretical pI 5.8), and the formation of rather large protein conjugate particles ( $48 \mathrm{~nm}$, see above). 


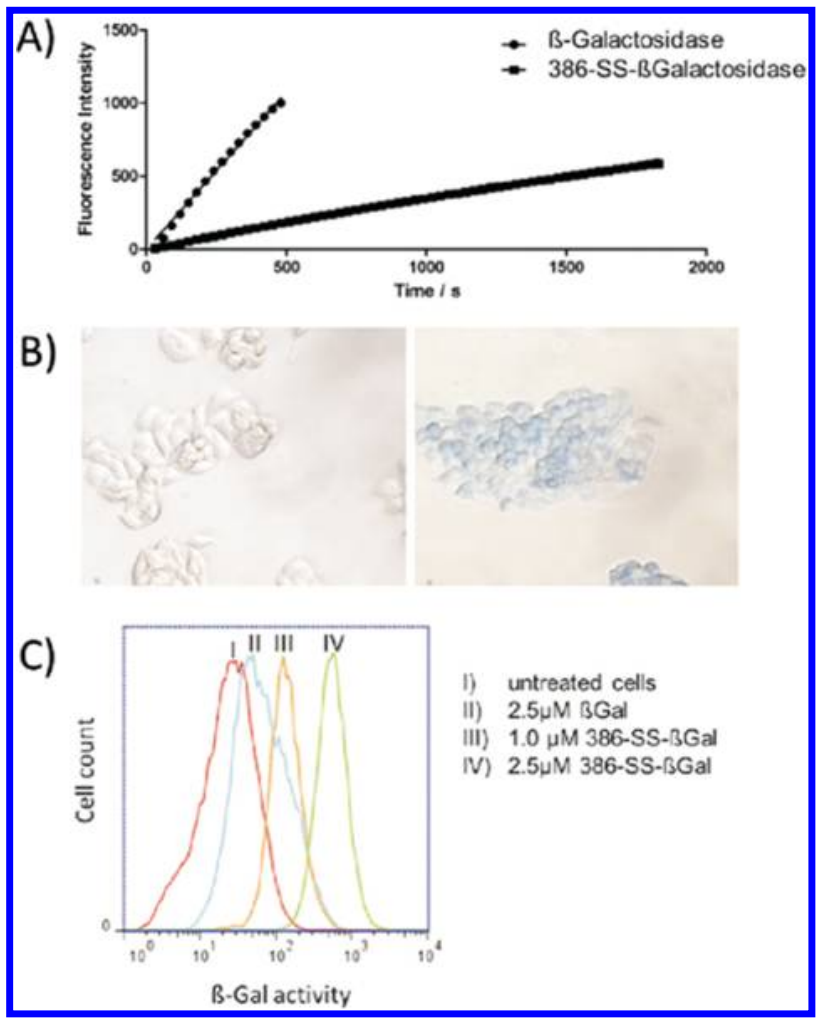

Figure 7. Transfection of Neuro2A cells with $\beta$-galactosidase. (A) Relative enzymatic activity of $\beta$-galactosidase after covalent modification with the SPDP linker and transfection oligomer 386. (B) Comparison of Neuro2A cells after treatment with unmodified, natural $\beta$-galactosidase (left) and 386-SS- $\beta$-galactosidase (right), washing, followed by incubation with X-Gal (5-bromo-4-chloro-indolyl- $\beta$-Dgalactopyranoside) substrate. (C) Flow cytometry of Neuro2A cells following transfection with different concentrations of 386-SS- $\beta$ galactosidase, washing, and incubation with C12-FDG substrate. Unmodified $\beta$-Gal was applied as control.

Nevertheless, Neuro2A cells transduced with 386-SS- $\beta$-Gal are able to hydrolyze the X-Gal (5-bromo-4-chloro-3-indoxyl- $\beta$-Dgalactopyranoside) substrate into $\beta$-galactose and the colored hydroxyindole product ${ }^{61}$ (Figure $7 \mathrm{~B}$ ). Only cells that were transduced with 386-SS- $\beta$-Gal (but not with unmodified $\beta$-Gal) were stained blue. For a more quantitative analysis, we used C12-FDG as the substrate, which led to FITC fluorescence after enzymatic cleavage. Fluorescence was quantified by flow cytometry, revealing fluorescence of the 386-SS- $\beta$-Gal transduced cells but not of cells transduced with unmodified $\beta$-Gal (Figure 7C). Data show that transfection oligomer 386 is able to transport remarkable amounts of active $\beta$-Gal enzyme into cells, even at the low transfection concentration of $1 \mu \mathrm{M}$.

Oligomer 386 was shown to exhibit low cytotoxicity when used as a carrier for siRNA or pDNA. ${ }^{44}$ To verify the nontoxic properties also in case of protein delivery, a cell viability test was performed. This confirmed this assumption. Figure 8 shows the low cytotoxicity of the transfection shuttle even at high concentrations. It exhibited only marginally higher effects on cell growth and metabolism than unmodified nlsEGFP protein or TAT-nlsEGFP. With the standard concentration used for the transfections above $(0.5 \mu \mathrm{M})$, a decline in metabolic activity of only $11 \%$ in comparison to that of growing untreated cells was observed ( $24 \mathrm{~h}$ after transfection). Even after transfection with $2.5 \mu \mathrm{M} 386$-SS-nlsEGFP, the metabolic cell activity decreased by only $29 \%$.

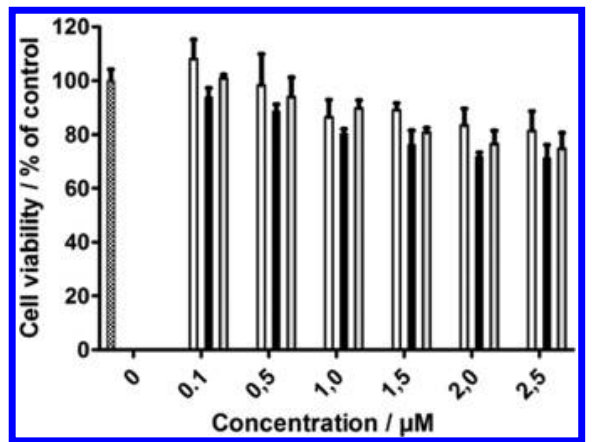

Figure 8. Cell metabolic activity assay (MTT assay) showing the low cytotoxicity of 386-SS-nlsEGFP, which is comparable to that of unmodified nlsEGFP. Data shows averages with standard deviations. Experiments were performed in quadruplicate. Metabolic activity was normalized to untreated cells (pattern-filled bar in the left). Metabolic activity of cells $24 \mathrm{~h}$ after transfection with unmodified nlsEGFP (white bars), with 386-SS-nlsEGFP (black bars), or with TATnlsEGFP (gray bars).

\section{CONCLUSIONS}

We have shown that a sequence-defined cationic transfection oligomer, with low molecular weight, is applicable to protein delivery upon covalent disulfide conjugation and enables high efficient uptake in two different cell lines. Protein transfection efficiency is linear dependent on cargo-carrier conjugate concentration as well as on transfection time. Endocytosis was demonstrated as the main uptake pathway. The carrier coupling to the cargo protein through a biological reversible disulfide bond results in natural subcellular behavior after endosomal release, as demonstrated in nuclear delivery for the nls-tagged EGFP protein. The chemically precise transfection shuttle is based on natural and artificial amino acids providing a $\mathrm{pH}$-responsive positive charge density (medium at extracellular $\mathrm{pH}$, high at endosomal $\mathrm{pH}$ ), resulting in efficient transfection (20 times more efficient than TAT peptide-mediated delivery). Furthermore, in contrast to polymeric carriers it has low molecular weight, exhibits no significant toxicity, and, when delivering an enzyme, was shown to maintain significant enzyme activity upon the transfection process. This technology is expected to be applicable to numerous other proteins.

\section{ASSOCIATED CONTENT}

\section{S Supporting Information}

SDS-PAGE showing molecular mass increase after modification with the $\mathbf{3 8 6}$ transfection oligomer and bioreversibility of the disulfide bonds between cargo and carrier. This material is available free of charge via the Internet at http://pubs.acs.org.

\section{AUTHOR INFORMATION}

\section{Corresponding Author}

*Phone: +49 892180 77840. Fax: +49 892180 77791. E-mail: Kevin.Maier@cup.uni-muenchen.de.

\section{Author Contributions}

I.M. designed and synthesized the carrier 386, K.M. performed the protein conjugations and the majority of the other experiments.

\section{Notes}

The authors declare no competing financial interest. 


\section{ACKNOWLEDGMENTS}

This work was supported by the DFG excellence cluster Nanosystems Initiative Munich (NIM). I.M. was a visiting Ph.D. student from IRB Barcelona, funded by the European Molecular Biology Organization through a short-term fellowship.

\section{ABBREVIATIONS}

nls, nuclear localization signal; EGFP, enhanced green fluorescent protein; SPDP, 3-(2-pyridyldithio)propionic acid $N$-hydroxysuccinimide ester; $\beta$-Gal, $\beta$-galactosidase; X-Gal, 5bromo-4-chloro-indolyl- $\beta$-D-galactopyranoside; C12-FDG, 5dodecanoylamino-fluorescein $\mathrm{di}-\beta$-D-galactopyranoside

\section{REFERENCES}

(1) Stolnik, S.; Shakesheff, K. Formulations for delivery of therapeutic proteins. Biotechnol. Lett. 2009, 31 (1), 1-11.

(2) Vincenzi, B.; Zoccoli, A.; Pantano, F.; Venditti, O.; Galluzzo, S. Cetuximab: from bench to bedside. Curr. Cancer Drug Targets 2010, 10 (1), 80-95.

(3) Frankel, A. D.; Pabo, C. O. Cellular uptake of the tat protein from human immunodeficiency virus. Cell 1988, 55 (6), 1189-1193.

(4) Green, M.; Loewenstein, P. M. Autonomous functional domains of chemically synthesized human immunodeficiency virus tat transactivator protein. Cell 1988, 55 (6), 1179-1188.

(5) Joliot, A.; Pernelle, C.; Deagostini-Bazin, H.; Prochiantz, A Antennapedia homeobox peptide regulates neural morphogenesis. Proc. Natl. Acad. Sci. U.S.A. 1991, 88 (5), 1864-1868.

(6) Dupont, E.; Prochiantz, A.; Joliot, A. Penetratin story: an overview. Methods Mol. Biol. 2011, 683, 21-29.

(7) Lindgren, M.; Langel, U. Classes and prediction of cellpenetrating peptides. Methods Mol. Biol. 2011, 683, 3-19.

(8) Chatelin, L.; Volovitch, M.; Joliot, A. H.; Perez, F.; Prochiantz, A. Transcription factor hoxa- 5 is taken up by cells in culture and conveyed to their nuclei. Mech. Dev. 1996, 55 (2), 111-117.

(9) Kilk, K.; Magzoub, M.; Pooga, M.; Eriksson, L. E.; Langel, U.; Graslund, A. Cellular internalization of a cargo complex with a novel peptide derived from the third helix of the islet- 1 homeodomain. Comparison with the penetratin peptide. Bioconjugate Chem. 2001, 12 (6), 911-916.

(10) Schwarze, S. R.; Ho, A.; Vocero-Akbani, A.; Dowdy, S. F. In vivo protein transduction: delivery of a biologically active protein into the mouse. Science 1999, 285 (5433), 1569-1572.

(11) June, R. K.; Gogoi, K.; Eguchi, A.; Cui, X. S.; Dowdy, S. F. Synthesis of a $\mathrm{pH}$-sensitive nitrilotriacetic linker to peptide transduction domains to enable intracellular delivery of histidine imidazole ring-containing macromolecules. J. Am. Chem. Soc. 2010, 132 (31), 10680-10682.

(12) Walsh, G. Biopharmaceutical benchmarks 2010. Nat. Biotechnol. 2010, 28 (9), 917-924.

(13) Verma, I. M.; Somia, N. Gene therapy - promises, problems and prospects. Nature 1997, 389 (6648), 239-242.

(14) McClung, J. K.; Kletzien, R. F. Analysis of BHK cell growth kinetics after microinjection of catalytic subunit of cyclic AMPdependent protein kinase. Mol. Cell. Biol. 1984, 4 (6), 1079-1085.

(15) Fenton, M.; Bone, N.; Sinclair, A. J. The efficient and rapid import of a peptide into primary $\mathrm{B}$ and $\mathrm{T}$ lymphocytes and a lymphoblastoid cell line. I. Immunol. Methods 1998, 212 (1), 41-48.

(16) Kaczmarczyk, S. J.; Sitaraman, K.; Young, H. A.; Hughes, S. H.; Chatterjee, D. K. Protein delivery using engineered virus-like particles. Proc. Natl. Acad. Sci. U.S.A. 2011, 108 (41), 16998-17003.

(17) Shi Kam, N. W.; Jessop, T. C.; Wender, P. A.; Dai, H. Nanotube molecular transporters: internalization of carbon nanotube-protein conjugates into Mammalian cells. J. Am. Chem. Soc. 2004, 126 (22), 6850-6851.

(18) Kam, N. W.; Liu, Z.; Dai, H. Carbon nanotubes as intracellular transporters for proteins and DNA: an investigation of the uptake mechanism and pathway. Angew. Chem., Int. Ed. 2006, 45 (4), 577581

(19) Slowing, I. I.; Trewyn, B. G.; Lin, V. S. Mesoporous silica nanoparticles for intracellular delivery of membrane-impermeable proteins. I. Am. Chem. Soc. 2007, 129 (28), 8845-8849.

(20) Bale, S. S.; Kwon, S. J.; Shah, D. A.; Banerjee, A.; Dordick, J. S.; Kane, R. S. Nanoparticle-mediated cytoplasmic delivery of proteins to target cellular machinery. ACS Nano 2010, 4 (3), 1493-1500.

(21) Liguori, L.; Marques, B.; Villegas-Mendez, A.; Rothe, R.; Lenormand, J. L. Liposomes-mediated delivery of pro-apoptotic therapeutic membrane proteins. J. Controlled Release 2008, 126 (3), 217-227.

(22) Debs, R. J.; Freedman, L. P.; Edmunds, S.; Gaensler, K. L.; Duzgunes, N.; Yamamoto, K. R. Regulation of gene expression in vivo by liposome-mediated delivery of a purified transcription factor. J. Biol. Chem. 1990, 265 (18), 10189-10192.

(23) Lissy, N. A.; Davis, P. K.; Irwin, M.; Kaelin, W. G.; Dowdy, S. F. A common E2F-1 and p73 pathway mediates cell death induced by TCR activation. Nature 2000, 407 (6804), 642-645.

(24) Jo, D.; Liu, D.; Yao, S.; Collins, R. D.; Hawiger, J. Intracellular protein therapy with SOCS3 inhibits inflammation and apoptosis. Nat. Med. 2005, 11 (8), 892-898.

(25) Sawant, R.; Torchilin, V. Intracellular transduction using cellpenetrating peptides. Mol Biosvst 2010, 6 (4), 628-640.

(26) Lee, Y.; Ishii, T.; Kim, H. J.; Nishiyama, N.; Hayakawa, Y.; Itaka, K.; Kataoka, K. Efficient delivery of bioactive antibodies into the cytoplasm of living cells by charge-conversional polyion complex micelles. Angew. Chem., Int. Ed. 2010, 49 (14), 2552-2555.

(27) Murata, H.; Futami, J.; Kitazoe, M.; Yonehara, T.; Nakanishi, H.; Kosaka, M.; Tada, H.; Sakaguchi, M.; Yagi, Y.; Seno, M.; Huh, N. H.; Yamada, H. Intracellular delivery of glutathione S-transferase-fused proteins into mammalian cells by polyethylenimine-glutathione conjugates. I. Biochem. 2008, 144 (4), 447-455.

(28) Futami, J.; Kitazoe, M.; Maeda, T.; Nukui, E.; Sakaguchi, M.; Kosaka, J.; Miyazaki, M.; Kosaka, M.; Tada, H.; Seno, M.; Sasaki, J.; Huh, N. H.; Namba, M.; Yamada, H. Intracellular delivery of proteins into mammalian living cells by polyethylenimine-cationization. J. Biosci. Bioeng. 2005, 99 (2), 95-103.

(29) Lee, Y.; Ishii, T.; Cabral, H.; Kim, H. J.; Seo, J. H.; Nishiyama, N.; Oshima, H.; Osada, K.; Kataoka, K. Charge-conversional polyionic complex micelles-efficient nanocarriers for protein delivery into cytoplasm. Angew. Chem. Int. Ed. 2009, 48 (29), 5309-5312.

(30) Didenko, V. V.; Ngo, H.; Baskin, D. S. Polyethyleneimine as a transmembrane carrier of fluorescently labeled proteins and antibodies. Anal. Biochem. 2005, 344 (2), 168-173.

(31) Yan, M.; Du, J.; Gu, Z.; Liang, M.; Hu, Y.; Zhang, W.; Priceman, S.; Wu, L.; Zhou, Z. H.; Liu, Z.; Segura, T.; Tang, Y.; Lu, Y. A novel intracellular protein delivery platform based on single-protein nanocapsules. Nat. Nanotechnol. 2010, 5 (1), 48-53.

(32) Mai, J. C.; Shen, H.; Watkins, S. C.; Cheng, T.; Robbins, P. D. Efficiency of protein transduction is cell type-dependent and is enhanced by dextran sulfate. I. Biol. Chem. 2002, 277 (33), 3020830218.

(33) Dalkara, D.; Zuber, G.; Behr, J. P. Intracytoplasmic delivery of anionic proteins. Mol. Ther. 2004, 9 (6), 964-969.

(34) Dalkara, D.; Chandrashekhar, C.; Zuber, G. Intracellular protein delivery with a dimerizable amphiphile for improved complex stability and prolonged protein release in the cytoplasm of adherent cell lines. J. Controlled Release 2006, 116 (3), 353-359.

(35) Prochiantz, A. Messenger proteins: homeoproteins, TAT and others. Curr. Opin. Cell Biol. 2000, 12 (4), 400-406.

(36) Gump, J. M.; June, R. K.; Dowdy, S. F. Revised role of glycosaminoglycans in TAT protein transduction domain-mediated cellular transduction. I. Biol. Chem. 2010, 285 (2), 1500-1507.

(37) Nakase, I.; Takeuchi, T.; Tanaka, G.; Futaki, S. Methodological and cellular aspects that govern the internalization mechanisms of arginine-rich cell-penetrating peptides. Adv. Drug Delivery Rev. 2008, 60 (4-5), 598-607. 
(38) Duchardt, F.; Fotin-Mleczek, M.; Schwarz, H.; Fischer, R.; Brock, R. A comprehensive model for the cellular uptake of cationic cell-penetrating peptides. Traffic 2007, 8 (7), 848-866.

(39) Stewart, K. M.; Horton, K. L.; Kelley, S. O. Cell-penetrating peptides as delivery vehicles for biology and medicine. Org. Biomol. Chem. 2008, 6 (13), 2242-2255.

(40) Madani, F.; Lindberg, S.; Langel, U.; Futaki, S.; Graslund, A. Mechanisms of cellular uptake of cell-penetrating peptides. J. Biophys. 2011, 2011, 414729.

(41) Patel, L. N.; Zaro, J. L.; Shen, W. C. Cell penetrating peptides: intracellular pathways and pharmaceutical perspectives. Pharm. Res. 2007, 24 (11), 1977-1992.

(42) Green, I.; Christison, R.; Voyce, C. J.; Bundell, K. R; Lindsay, M. A. Protein transduction domains: are they delivering? Trends Pharmacol. Sci. 2003, 24 (5), 213-215.

(43) Wagner, E. Polymers for siRNA delivery: inspired by viruses to be targeted, dynamic, and precise. Acc. Chem. Res. 2012, 45, 10051013.

(44) Schaffert, D.; Troiber, C.; Salcher, E. E.; Frohlich, T.; Martin, I.; Badgujar, N.; Dohmen, C.; Edinger, D.; Klager, R.; Maiwald, G.; Farkasova, K.; Seeber, S.; Jahn-Hofmann, K.; Hadwiger, P.; Wagner, E. Solid-phase synthesis of sequence-defined $\mathrm{T}$-, $\mathrm{i}$-, and U-shape polymers for pDNA and siRNA delivery. Angew. Chem., Int. Ed. 2011, 50 (38), 8986-8989.

(45) Frohlich, T.; Edinger, D.; Klager, R.; Troiber, C.; Salcher, E.; Badgujar, N.; Martin, I.; Schaffert, D.; Cengizeroglu, A.; Hadwiger, P.; Vornlocher, H. P.; Wagner, E. Structure-activity relationships of siRNA carriers based on sequence-defined oligo (ethane amino) amides. J. Controlled Release 2012, 160 (3), 532-541.

(46) Yu, H.; Russ, V.; Wagner, E. Influence of the molecular weight of bioreducible oligoethylenimine conjugates on the polyplex transfection properties. AAPS I. 2009, 11 (3), 445-455.

(47) Saito, G.; Swanson, J. A.; Lee, K. D. Drug delivery strategy utilizing conjugation via reversible disulfide linkages: role and site of cellular reducing activities. Adv. Drug Deliverv Rev. 2003, 55 (2), 199215.

(48) Xie, H.; Braha, O.; Gu, L. Q.; Cheley, S.; Bayley, H. Singlemolecule observation of the catalytic subunit of cAMP-dependent protein kinase binding to an inhibitor peptide. Chem. Biol. 2005, 12 (1), 109-120.

(49) Maier, K.; Wagner, E. Acid-labile traceless click linker for protein transduction. I. Am. Chem. Soc. 2012, 134 (24), 10169-10173.

(50) Tada, S.; Chowdhury, E. H.; Cho, C. S.; Akaike, T. pH-sensitive carbonate apatite as an intracellular protein transporter. Biomaterials 2010, 31 (6), 1453-1459.

(51) McGuire, J. B.; James, T. J.; Imber, C. J.; St Peter, S. D.; Friend, P. J.; Taylor, R. P. Optimisation of an enzymatic method for betagalactosidase. Clin. Chim. Acta 2002, 326 (1-2), 123-129.

(52) Henriques, S. T.; Costa, J.; Castanho, M. A. Translocation of beta-galactosidase mediated by the cell-penetrating peptide pep-1 into lipid vesicles and human HeLa cells is driven by membrane electrostatic potential. Biochemistry 2005, 44 (30), 10189-10198.

(53) Ayame, H.; Morimoto, N.; Akiyoshi, K. Self-assembled cationic nanogels for intracellular protein delivery. Bioconjugate Chem. 2008, 19 (4), 882-890.

(54) Barnes, M. P.; Shen, W. C. Disulfide and thioether linked cytochrome c-oligoarginine conjugates in HeLa cells. Int. J. Pharm. 2009, 369 (1-2), 79-84.

(55) Meyer, M.; Dohmen, C.; Philipp, A.; Kiener, D.; Maiwald, G.; Scheu, C.; Ogris, M.; Wagner, E. Synthesis and Biological Evaluation of a Bioresponsive and Endosomolytic siRNA-Polymer Conjugate. Mol. Pharmaceutics 2009, 6 (3), 752-762.

(56) Mueller, J.; Kretzschmar, I.; Volkmer, R.; Boisguerin, P. Comparison of cellular uptake using $22 \mathrm{CPPs}$ in 4 different cell lines. Bioconiugate Chem. 2008, 19 (12), 2363-2374.

(57) Rejman, J.; Oberle, V.; Zuhorn, I. S.; Hoekstra, D. Sizedependent internalization of particles via the pathways of clathrin- and caveolae-mediated endocytosis. Biochem. I. 2004, 377 (Pt 1), 159-169.
(58) Aoyama, Y.; Kanamori, T.; Nakai, T.; Sasaki, T.; Horiuchi, S.; Sando, S.; Niidome, T. Artificial viruses and their application to gene delivery. Size-controlled gene coating with glycocluster nanoparticles. I. Am. Chem. Soc. 2003, 125 (12), 3455-3457.

(59) Nakai, T.; Kanamori, T.; Sando, S.; Aoyama, Y. Remarkably sizeregulated cell invasion by artificial viruses. Saccharide-dependent selfaggregation of glycoviruses and its consequences in glycoviral gene delivery. I. Am. Chem. Soc. 2003, 125 (28), 8465-8475.

(60) Osaki, F.; Kanamori, T.; Sando, S.; Sera, T.; Aoyama, Y. A quantum dot conjugated sugar ball and its cellular uptake. On the size effects of endocytosis in the subviral region. J. Am. Chem. Soc. 2004, 126 (21), 6520-6521.

(61) Horwitz, J. P.; Chua, J.; Curby, R. J.; Tomson, A. J.; Da Rooge, M. A.; Fisher, B. E.; Mauricio, J.; Klundt, I. Substrates for cytochemical demonstration of enzyme activity. I. Some substituted 3 -indolyl- $\beta$-Dglycopyranosides 1a. I. Med. Chem. 1964, 7 (4), 574-575. 